\title{
HIGHLIGHTS
}

VACCINES

\section{Smallpox vaccine dogma challenged}

The widely held belief that the smallpox vaccine only provides protection against smallpox for $3-5$ years is untrue, according to a new study in Nature Medicine.

The vaccine, which was routinely administered in the United States until 1972, comprises live vaccinia virus, an orthopoxvirus that is closely related to variola, the causative agent of smallpox. In the largest study of its kind so far, a team of researchers at Oregon Health and Science University analysed the antiviral immune response in 306 volunteers who had been vaccinated against smallpox at least once in their lifetime. The timing of the vaccinations varied from between one month before testing to 75 years before testing.

The cell-mediated immune response was quantified using an $e x$ vivo assay that detects the production of interferon $\gamma($ IFN- $\gamma)$ and tumour necrosis factor $\alpha$ (TNF- $\alpha$ ) by peripheral blood mononuclear cells following direct challenge with vaccinia. The smallpox vaccine stimulates a strong virus-specific $\mathrm{CD} 4^{+}$and $\mathrm{CD} 8^{+} \mathrm{T}$ cell response, which declines slowly with an average half-life of 8-15 years.

Hammarlund et al. then used a vaccinia-specific ELISA and a neutralization assay to detect vacciniaspecific antibodies. In contrast to the cell-mediated response, the humoral immune response was shown to remain steady for as long as 75 years and could therefore play a greater role in smallpox immunity than was previously thought.
It has long been maintained that repeated vaccination against smallpox is required for maximal protection against the disease. However, analysis of the immune response of volunteers who had been immunised more than once revealed that although repeated vaccination resulted in a short-term boost in immune responses, it did not significantly increase the levels of long-term cell-mediated or humoral immunity.

These results suggest that the prevailing immunity to smallpox in the general population in the United States is much greater than was previously thought. More than $90 \%$ of the participants in the study exhibited measurable cell-mediated or humoral immunity to smallpox. Given that more than $90 \%$ of Americans over the age of 35 - some 140-150 million individuals - have been vaccinated against smallpox, this could provide at least some degree of herd immunity in the event of an outbreak.

Sheilagh Clarkson

\section{(D) References and links}

ORIGINAL RESEARCH PAPER Hammarlund, E. et al. Duration of antiviral immunity after smallpox vaccination. Nature Med. 2003

(doi:10.1038/nm917).

FURTHER READING Smith, G.L. \& McFadden, G. Smallpox: anything to declare? Nature Rev. Immunol. 2, 521-527 (2002).

WEB SITES

Mark Slifka's lab:

http://www.ohsu.edu/vgt//lifka.htm

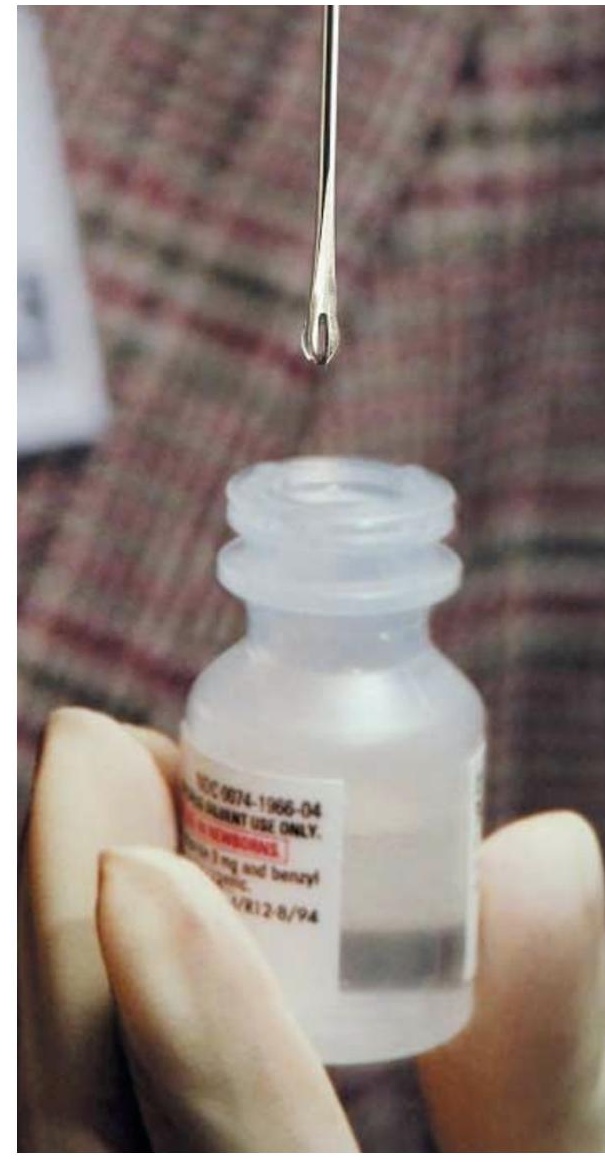

CDC/James Gathany 